\title{
Integrated technology of design, construction and management for wharf engineering based on BIM A case study of the liquefied hydrocarbon wharf in Jiangsu
}

\author{
Wenwen Zhang ${ }^{1, a^{*}}$,Qiujie Li ${ }^{1}$, Qijin Zhou ${ }^{1}$, Zixi Sha ${ }^{1}$, Xianbo Jiang ${ }^{1}$, Haorui Sun ${ }^{1}$ \\ ${ }^{1}$ Department of Construction Engineering Tianjin Renai College Tianjin, China
}

\begin{abstract}
With the development of technology, BIM can be gradually applied in the wharf engineering, but due to the specialties coexistence, there are still some problems. Based on the liquefied hydrocarbon wharf in Jiangsu, it is explored and summarized the application of BIM in wharf engineering design, construction and management, so it solves the problems of collaborative design, simulation construction, real-time sharing of the collaborative platform, etc. It provides a set of effective schemes and reference cases for the application of BIM in wharf engineering.
\end{abstract}

\section{Introduction}

BIM is a complex including geometric appearance and engineering database, which aims to improve the planning, design, construction and operation and maintenance management level of construction projects.

General wharf engineering includes many specialties, such as wharf hydraulic structure, process, HVAC, water supply and drainage, power supply, control and auxiliary building. Under the traditional design mode, the plane drawings are difficult to meet the design requirements, and the point-to-point single line communication between specialties based on plane drawings has low efficiency. There are many changes in construction, low efficiency in cooperation and great difficulty in project management. In recent years, the advantages of BIM Technology cater to the development trend of specialization, automation and integration in water transportation industry[1]. BIM 5D technology is not only more accurate and efficient in wharf design, but also redefines the construction simulation to realize project fine management.

$\mathrm{Hu}$ Ling introduced BIM Technology into the construction of Yangshan Port Phase IV high piled wharf, and achieved remarkable results in engineering parameterization, visualization and collaboration through modeling, construction simulation, collision inspection and other means[2]. Using Autodesk and Dassault series software, Chai Guowei made visual modeling, parameterized design, engineering quantity statistics and scheme display in the project of automobile passenger and cargo ro-ro wharf in Xinhai Port area[3]. Taking a new overseas container terminal as an example, Lin Chen anpan explored a set of BIM application technology routes and solutions for wharf engineering from software selection, design process, model application to data exchange[4].
It takes a liquefied hydrocarbon wharf in Jiangsu as an example to introduce the application of BIM technology in the structural design, construction and project management of wharf engineering.

\section{Application of BIM in design}

BIM Technology is used to simulate the underwater environment and perform underwater and water modeling. According to the specified force layer and relevant geotechnical and hydrological parameters, the influence of underwater conditions on hydraulic structures can be simulated and determined.

There is no corresponding family library for wharf structure in the existing family library of REVIT, so it is necessary to establish and design corresponding family libraries for different wharf structures. Family is the smallest independent data unit of BIM building informatization, the component of the project, and the carrier of parameter information. These parameters can also make the engineering design and consumption calculation more accurate and fast.

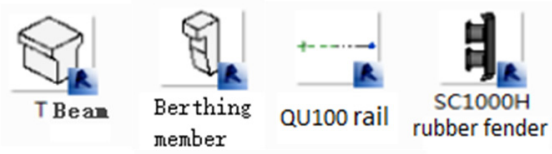

Fig1. Some families for wharf structures.

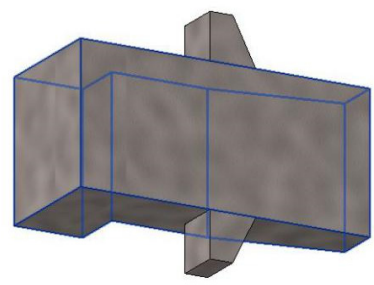

Fig2.3D model of berthing member.

a* Corresponding author : 15922109195@vip.163.com 
BIM breaks the traditional CAD chains of drawing first and then summarizing, and realizes simultaneous modeling on a collaborative platform. Collisions and other problems can be found in time and solved through joint negotiation. Parameterized wharf structure family library also makes it easier to change and modify.

For example, the liquefied hydrocarbon wharf of this project, its property determined the complexity of its pipeline system. Pipeline system was a complex process of highly centralized multi-disciplinary cooperation in a limited space. Under the traditional design mode, pipeline and structure belonged to two departments, so the collision between each part was very easy. Through the BIM collaborative platform, the design process was improved, the information communication was timely and accurate, and the efficiency of collaborative design was greatly improved. The mobile terminal could also be used to collect the graphic data of the progress, quality, safety and other aspects of the construction site directly, and upload them to the corresponding parts of the BIM model, so that problems could be found in time and intuitively.
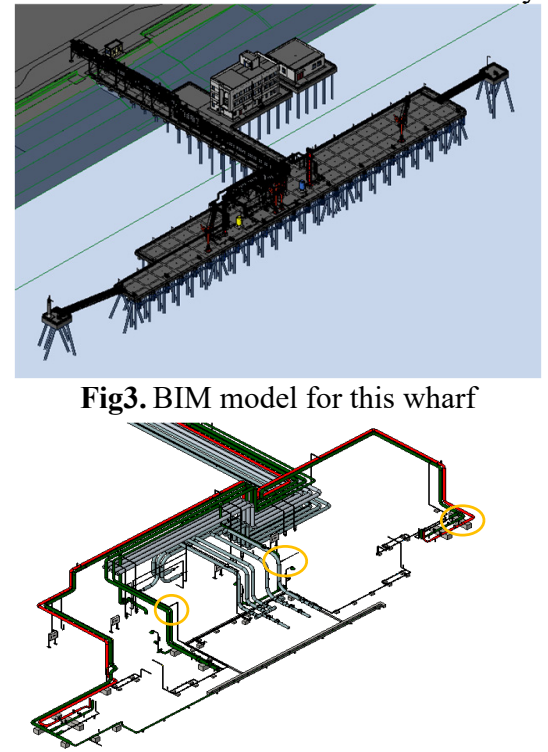

Fig4. Pipes collisions check in BIM model

\section{Application of BIM in Construction}

\subsection{Construction of cast-in-place beam}

Due to the large quantity and tight construction period of cast-in-place beam, its construction progress directly affected the subsequent installation of precast beams and slabs, which was related to the overall construction progress and ship machinery equipment scheduling of the project. Therefore, the cast-in-place beam construction quality and progress had a decisive impact on the whole project.

In this project, the depth above LOD300 of Revit software was used for modeling. With the help of BIM5D technology, the construction simulation and progress control were carried out, the material management was further compared with the three calculations, so as to improve the efficiency of ships and machinery.

The internet of things technology was used in the construction to track the component status through $\mathrm{QR}$ code. The data statistical analysis was formed, and the component status was updated in real time.

Through the display of the virtual model, it could achieve the effect of a physical model while saving the project cost. Through the dynamic video process disclosure, it could make managers and workers more clearly understand the whole construction process. Upload the virtual model to the cloud platform, everyone could browse anytime and anywhere, convenient and fast.

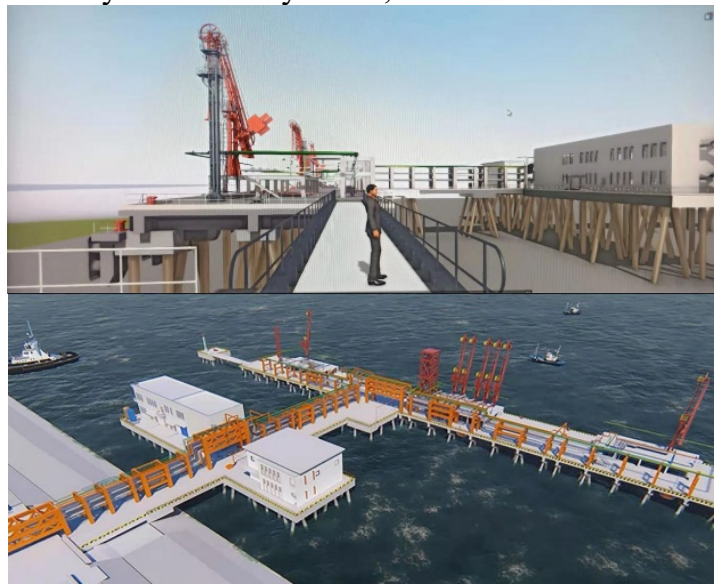

Fig5. Dynamic simulation screenshots of construction process

\subsection{Precast component}

There were a large number of precast components in this project, and they were all prestressed components. At the same time, the elevation of component installation position is diversified. Installation sequence was particularly important. Prestressed pipe frame beams and prestressed hollow slabs were precast in the casting yard and transported to the site by sea. Therefore, the precast components will greatly affect the whole project.

Taking the advantages of the BIM collaborative platform, the construction party could query and modify the production plan of the casting yard anytime and anywhere. The mobile phone would record the components on site and keep track of progress anytime and anywhere. It realized the visual presentation of project progress, the traceability and summary of acceptance

\subsection{Comprehensive pipe network}

This project was a liquefied hydrocarbon wharf with complex and diverse pipeline types. There were also construction difficulties at the intersection of bored pile breakwater and pipe gallery. It was difficult to control the construction quality and safety.

There were many construction teams in the comprehensive pipeline network and the cross construction was frequent, so, the general contractor should try to reduce the mutual interference between the construction teams in the organization and coordination. At the same time, the protection of completed construction should be strengthened, and some temporary protection measures should be taken if necessary.

With the assistance of BIM, the pipeline position was adjusted without violating the principles of the design 
institute to facilitate construction. The construction scheme was visually displayed through the $3 \mathrm{D}$ technology construction simulation, making the three-level disclosure more intuitive.

In the process of pipe network installation, the advantages of the BIM collaborative platform were utilized to make good construction arrangement. The installation time and sequence of various pipelines were reasonably adjusted to intersperse the construction, so as to avoid idling.

Through the platform, the progress, quality, safety, data and other information in the intersection construction were managed throughout the whole process. Problems could be quickly traced to the cause, so that the company could issue solutions in time. The quality and safety issues during the construction process were inspected, and the installed parts were debugged to ensure the smooth operation of the integrated pipe network.

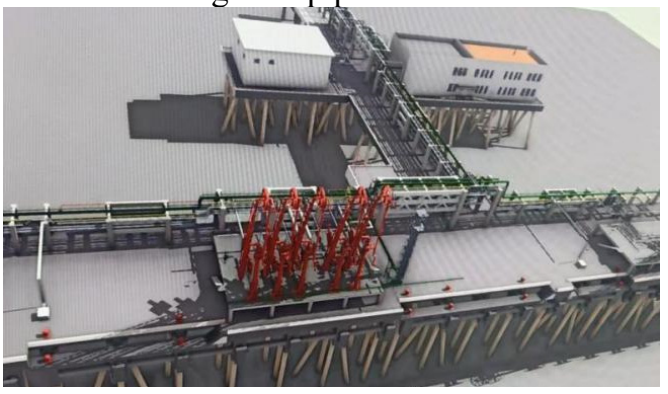

Fig6. Dynamic simulation screenshots of pipes installation

\subsection{Combination of construction method simulation and first piece system}

In order to reduce the rework and material waste in construction, prevent and eliminate the common quality problems, the first piece system was usually used in engineering to ensure the correct and feasible process.

Through BIM5D technology, every new activity of this project was simulated according to the design. In the simulation, the raw material control, manufacturing and operation were standardized, and the construction personnel, types of work, materials, machinery and equipment were determined. Then the first piece was produced according to this standard construction sequence No large-scale construction should be carried out before the first piece acceptance had not been passed.

Taking the advantages of the collaborative platform, each construction team used the first piece as a reference standard to construct separately. The acceptance of components could be mastered at any time; the acceptance link was transparent and efficient, and the acceptance could be traced and summarized.

\subsection{Sectional flow construction based on BIM5D}

The traditional sectional flow management in the charge of a special personnel of regional head, but it is still difficult to achieve perfect management. Sectional flowing construction is always unsmooth due to insufficient preliminary preparations and cross-activities.

The project had a large scale and many types of work.
Therefore, BIM platform and construction simulation were used to divide the flow section, thereby reducing the input of construction labor, fully improving the efficiency of construction labor, avoiding the labor idleness, ensuring the integrity of the project structure, and improving the project quality.

With BIM5D, after dividing the model into flow sections according to the actual scene, the on-site measurement and verification was very convenient and quick. The flow construction work of the whole project no longer required special personnel to be responsible. All flow section related information could be extracted in the software. The level of refined construction management had been improved through functions such as advance preparation and flow construction simulation.

\section{Application of BIM in project management}

\subsection{Schedule management based on BIM}

Project schedule management is the key content of project management. In the original project management mode, planned and actual performance cannot be presented directly, which often leads to a serious disconnect between planed and actual performance. As this wharf project involved offshore construction, weather and hydrological conditions had a great impact on the construction schedule, and some construction activities were more complicated, so the BIM technology had been used to make elaborate schedule management and activities division.

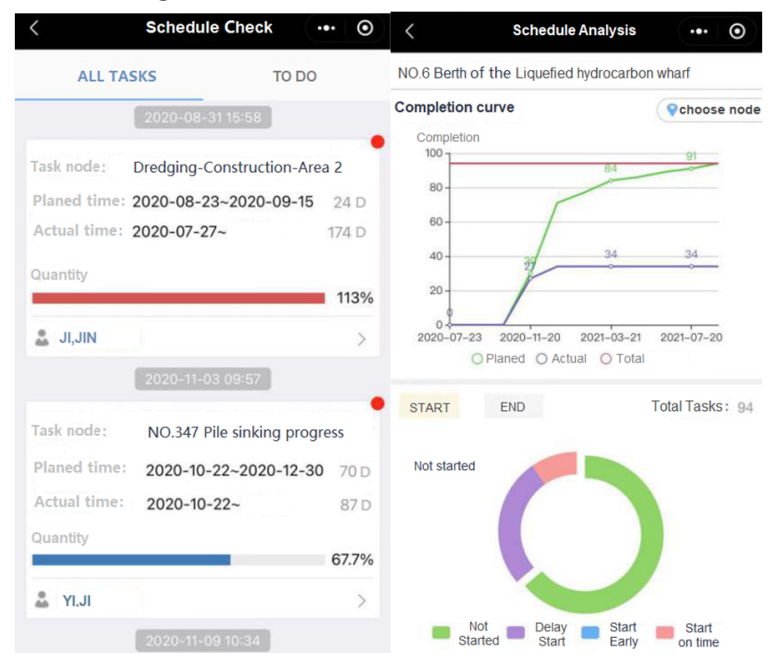

Fig7. Schedule check and analysis in BIM collaborative platform

The construction schedule was simulated based on the BIM model, and the project department was able to prepare the required materials in advance, avoiding schedule delays caused by human causes, and realizing the dynamic management and linkage modification of the schedule. The 3D model visually displayed the comparison between the planned performance and the actual performance, which could summarize and analyze the main reasons for the delay and advance of the schedule, summarized the experience to provide a basis for the next scheduling. With elaborate schedule management and 
activities division, when uncontrollable factors such as construction environment, policies, funds affected the progress, the project department could quickly issue solutions, adjust plans, and ensure the total construction period.

\subsection{Web application based on BIM}

In the collaborative management of construction projects, problems such as poor communication, delay in obtaining information and difficulty in unified management of data often lead to project rework and disputes, which affect the normal development of the project.

Compared with general projects, this wharf project had more participants, remote construction sites, inconvenient transportation, and complicated offshore construction.

With the assistance of BIM, this project created a web page, which enabled the participants to see the data in the model through the web, query and understand the project situation from multiple dimensions. It ensured smooth communication, correct information transmission and consistent behavior between different participants, different specialties and different positions, and provided a guarantee for the cooperation of all participants in the project.

The owner and the general contractor could manage the project remotely in different places, and view the latest developments of the project conveniently and intuitively at any time, including the project progress, cost, quality, safety and other relevant information.

\subsection{Project payment and data sharing}

The owner usually measures, calculates and confirms the completed project quantity according to the contract, calculates the payable amount for the confirmed project quantity and pays the progress payment to the general contractor. The general contractor also needs to pay the subcontractors according to the actual situation.

The BIM collaborative platform of this project recorded the completion of the activities and on-site visa status. The contractor could quickly count the completed quantities of the bill of, and quickly complete the progress payment application to the owner and the review of the subcontracted quantities. At the same time, the components were associated with budget documents, subcontracts, construction drawings, project schedule. Different participants could filter the bill quantities and subcontracted quantities according to according to multidimensionality such as specialty, schedule (time), flow section.

During the construction,the long project period, the various data and different participants holding different data leads to the difficulty of data query, incomplete preservation and inconvenient project data management.

The BIM collaborative platform of this project realized the cloud storage of project data. The model contained all the information in the process of project design and construction, which ensured the comprehensiveness and intuitiveness of the information, so as to facilitate the unified management and convenient access to the data.
Project participants could filter the data they need in multiple dimensions, and the software could quickly generate various reports for the participants to analyze and summarize the data. The 3D completed model would be of great significance to the operation and maintenance of the project.

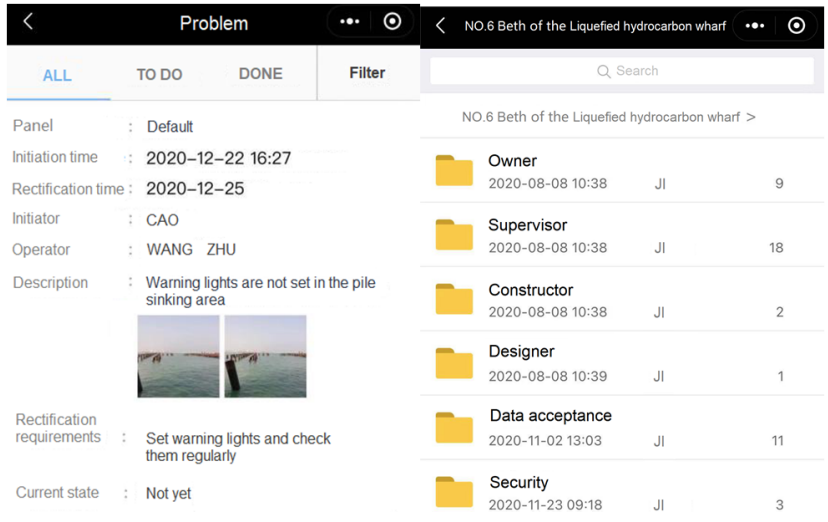

Fig8. Data sharing in BIM collaborative platform

\section{Conclusion}

1) This project realized the application and exploration of BIM technology in the design of wharf engineering. It gave full play to the advantages of BIM Technology in visualization, collaborative and parametric design, greatly improved the design efficiency and reduces the design error rate.

2) In the project construction based on BIM, all specialties and positions were based on the same model, engineering quantity data and material data were accurate and unified, data were transparent and shared in real time through the Internet mode. It provided data for all management decisions, and project management could be more elaborate to the component.

3) At present, the application of BIM technology in the water transportation industry is developing slowly, and there are still problems, such as insufficient software support and lack of talents, which restrict the application and promotion of BIM Technology. There are still a lot of problems in the promotion of BIM technology that need to be solved step by step through further research and engineering practice.

\section{References}

1. Zhang, W. (2017) Function of BIM Technology in Port Engineering. Port Technology, 5: 49-52.

2. Hu, L. (2020) Application of BIM technology in Yangshan Phase IV wharf project. Port and Waterway Engineering ,11: 151-154.

3. Chai, G., Zhan,K. (2020) Discussion on Application of BIM Technique in Port Engineering Design. Port Engineering Technology. 57: 83-87.

4. Lin, C., Chen, L., Qian, Y. (2020) Application of BIM Technique in Design of a Container Terminal. Port Engineering Technology. 57: 71-76. 